\title{
Simultaneous Employment of the FRAIL Scale and the Tilburg Frailty Indicator May Identify Elderly People Who Require Different Interventional
} \section{Strategies}

\author{
Magdalena Sacha $\mathbb{I D}^{\prime}$ \\ Jerzy Sacha $\mathbb{D}^{2,3}$ \\ Katarzyna \\ Wieczorowska-Tobis $\mathbb{D}^{\prime}$ \\ 'Department of Palliative Medicine, \\ Poznan University of Medical Sciences, \\ Poznan, Poland; ${ }^{2}$ Faculty of Physical \\ Education and Physiotherapy, Opole \\ University of Technology, Opole, Poland; \\ ${ }^{3}$ Department of Cardiology, University \\ Hospital in Opole, Opole, Poland
}

This article was published in the following Dove Press journal: Clinical Interventions in Aging

\begin{abstract}
Purpose: Frailty is a geriatric syndrome that is usually considered as a set of physical deficits (unidimensional concept); however, it can also concern the psychological and social domains of human functioning (multidimensional concept). The FRAIL scale is a diagnostic tool which ascertains only physical frailty, whereas the Tilburg Frailty Indicator (TFI) is a diagnostic instrument for multidimensional frailty. The study investigates if non-robust physical status and multidimensional frailty affect the same individuals and whether simultaneous employment of the FRAIL scale and TFI identifies specific subgroups of elderly people which require different interventions.
\end{abstract}

Patients and Methods: In this cross-sectional study, 1024 community dwelling elderly individuals at the age of 65 years or older (mean age $72.6 \pm 6.3$ years; range 65-93 years) were evaluated with the FRAIL scale and TFI.

Results: According to the FRAIL scale, $52.9 \%$ of the subjects were physically non-robust, but according to TFI, $54.6 \%$ presented multidimensional frailty. These two diagnostic tools were concordant in their outcomes in $77.1 \%$ (ie, $42.3 \%$ of individuals were physically and multidimensionally frail but $34.8 \%$ were robust according to both two instruments); however, in $22.9 \%$ the outcomes were discordant. Consequently, by simultaneous employment of the FRAIL scale and TFI, four distinct functional categories have been distinguished: (i) nonrobust physical status with multidimensional frailty, (ii) exclusive non-robust physical status, (iii) exclusive multidimensional frailty, and (iv) full robust status.

Conclusion: By applying simple physical and multidimensional frailty diagnostic tools, subgroups of elderly people may be identified that require specific management strategies to improve their functional status.

Keywords: physical frailty, multidimensional frailty, psychological frailty, social frailty, aging, functional status

\section{Introduction}

Frailty is a pre-clinical condition concerning the elderly population which predisposes to numerous adverse outcomes and leads to disability, dependence, and ultimately to death. ${ }^{1,2}$ Frailty may be diagnosed with different tools, which are commonly categorized into two types of conceptualizations: unidimensional, based on the physical and biological dimension, and multidimensional, based on the associations between physical, psychological, and social domains of human functioning. ${ }^{3-5}$ For frailty screening and prevention at the community level, simple
Correspondence: Jerzy Sacha Email sacha@op.pl 
and highly sensitive diagnostic instruments are paramount. Such tools should enable early identification of subjects at risk, and ideally, they should also permit self-assessment for quick detection of frailty symptoms. One of the most frequently used and extensively validated tools for physical frailty diagnosis is a Physical Frailty Phenotype (PFP), which considers five main frailty features: fatigue, weakness, slowness, low physical activity, and weight loss. However, this instrument requires some expertise and equipment (eg, a dynamometer), and therefore it is not convenient at the community level. ${ }^{2}$ A simpler alternative, recommended by the International Association of Nutrition and Aging Task Force, is a questionnaire named the FRAIL scale which consists of 5 questions directly corresponding to PFP. ${ }^{4,6}$ Both PFP and the FRAIL scale distinguish two functional states, ie, physical frailty and pre-frailty with a prevalence among community-dwelling elderly people of $6-13 \%$ and $35-50 \%$, respectively. ${ }^{7-9}$ Taking into account the pre-frailty state, these instruments are very sensitive in the detection of physical deficits associated with aging, and thus, they may be helpful in identifying subjects who require preventative interventions. ${ }^{10}$ With respect to multidimensional frailty, one of the most promising tools, which can be also used for self-assessment, is the Tilburg Frailty Indicator (TFI). This questionnaire addresses 15 frailty deficits arranged in three various dimensions, ie, physical, psychological, and social ones. ${ }^{5}$ The incidence of multidimensional frailty according to TFI is about $29-45 \%$. $^{7,8}$ Thus, this prevalence corresponds to the prevalence of physical frailty and pre-frailty taken as a single entity (ie, non-robust status). In one of the recent studies, the incidence of the non-robust physical status and the multidimensional frailty was $47 \%$ vs $45 \%$, respectively. ${ }^{8}$ Therefore, the following questions can be raised: (i) whether non-robust physical status and multidimensional frailty affect the same individuals; (ii) what the concordance and discordance between the FRAIL scale and TFI are; and (iii) whether simultaneous employment of the FRAIL scale and TFI identifies specific subgroups of elderly people which require different interventions.

\section{Materials and Methods}

\section{Study Population and Methods}

People at the age of 65 years or older living in a community in Opole District (southwest Poland) participated in this cross-sectional study. The participants completed a questionnaire by themselves which concerned physical and multidimensional frailty as well as some frailty risk factors. The study questionnaires were distributed during healthy lifestyle promoting meetings organized by local senior organizations in the period between December 2017 and December 2018 - in total, there were about 30 meetings during this period. Such open-access meetings were aimed at all elderly individuals living in the district and were advertised by suitable posters. The questionnaires were anonymous and included a short description of the study rationale and purpose. The research protocol was approved by the Ethics Committee at the Poznan University of Medical Sciences, and the study was conducted in accordance with the Declaration of Helsinki. All participants provided their informed consent.

Physical frailty was evaluated with the FRAIL scale which consisted of 5 elements related to physical tiredness/fatigue, inability to walk up one flight of stairs, inability to walk $200 \mathrm{~m}$, unexplained body mass loss, and a number of chronic diseases. ${ }^{4,6}$ Unexplained body mass loss was scored 1 if a subject reported a weight loss of $6 \mathrm{~kg}$ or more in the last six months, or $3 \mathrm{~kg}$ or more in the last month. The presence of 5 or more chronic diseases scored 1; otherwise, it was scored 0 (the subjects were asked about their relevant chronic diseases and no specific list of illnesses was provided). The FRAIL scale scores range from 0 to 5 and may imply frail (3-5), pre-frail (1-2), and robust status (0)., 4

Multidimensional frailty was investigated with part B of the Tilburg Frailty Indicator (TFI) which consisted of 15 frailty deficits arranged in three dimensions. The physical dimension ( $0-8$ points) contained eight items related to poor physical health, unintentional weight loss, difficulty in walking, difficulty in maintaining balance, poor hearing, poor vision, lack of strength in hands, and physical tiredness. The psychological dimension (0-4 points) consisted of four items associated with problems with memory, feeling down, feeling nervous or anxious, and inability to cope with problems. The social dimension (0-3 points) contained three items related to living alone, missing other people, and lack of support from other people. The TFI score may range from 0 to 15 , and frailty is recognized if the TFI score is at least $5 .^{5}$ Part A of TFI investigated frailty risk factors including age, gender, education level, economic status, lifestyle, marital status, experiences with different unfavorable events in the recent time, and satisfaction with living conditions. ${ }^{5}$ The TFI was adapted and validated for the Polish population by Uchmanowicz et al. ${ }^{11,12}$ 


\section{Statistical Analysis}

Descriptive data are presented as mean \pm standard deviation (SD) or frequency and percentage as appropriate. The normality of the variables was tested using the Kolmogorov-Smirnov test and visual inspection of histograms. Although some data did not exhibit a normal distribution, they were presented as mean $\pm \mathrm{SD}$ to enable numerical comparisons. The non-parametric KruskalWallis test was used to test differences between several continuous variables and the Bonferroni multiple comparison test was employed for posthoc analyses, and the Tukey-Kramer's posthoc procedure was used to calculate the multiple comparison $P$-values. The chi-square test was used for multiple comparisons of categorical variables. A posthoc analysis of residuals in contingency tables with an adjusted $P$-value for multiple comparisons was employed to determine which observed frequencies differed significantly from expected frequencies. ${ }^{13}$ A $P$-value of less than 0.05 was considered as the level of statistical significance. Analyses were conducted using the Statistical Package for Social Sciences (SPSS, v. 22.0, IBM SPSS Statistics, IBM Corporation, Chicago, IL, USA), and NCSS 12 Statistical Software (2018), NCSS, LLC, Kaysville, Utah, USA, ncss.com/software/ncss.

\section{Results}

One thousand twenty-four community-dwelling elderly individuals at the age of 65 years or older (mean age $72.6 \pm 6.3$ years; range $65-93$ years) took part in this cross-sectional study. The participants' characteristics are presented in Table 1. Most of them were female, lived in a city, had a former intellectual occupation, a high school or university education level, and a moderate economic status, and they usually declared a partially healthy or healthy lifestyle and satisfaction with living conditions. Only a minority of the subjects suffered from a serious illness in the recent time, and on average, they reported 1.9 \pm 1.6 chronic diseases. Half of them lived in a relationship; however, some individuals had experienced death or serious illness of a loved person or end of an important relationship in the recent time. Almost 45\% participated in senior organizations, and in general, they rarely experienced a traffic or criminal event. With respect to physical frailty, the mean total FRAIL scale score was $0.8 \pm 0.9$ with a prevalence of frailty, pre-frailty, and non-robust status of $6.3 \%, 46.7 \%$, and $52.9 \%$, respectively. Regarding single components of the FRAIL scale, the most prevalent was physical tiredness/fatigue (45.4\%); however, the prevalence of other components did not exceed $13 \%$. The incidence of multidimensional frailty was $54.6 \%$ with the mean TFI total score of $5.4 \pm 3.1$. The following TFI components presented the highest prevalence: missing other people (66.6\%), feeling nervous or anxious $(65.9 \%)$, and feeling down $(65.5 \%)$ - these components represent social and psychological dimensions (Table 1).

In most of the cases (ie, in 77.1\%), the FRAIL scale and TFI were concordant in their outcomes, ie, $42.3 \%$ of individuals were physically and multidimensionally frail but $34.8 \%$ were robust according to both two instruments. However, in almost one-quarter (ie, 22.9\%) these two tools were discordant, yielding two functional categories, ie, exclusive non-robust physical status (physical frailty or pre-frailty) or exclusive multidimensional frailty with the respective prevalence of $10.6 \%$ and $12.3 \%$. Thus, by simultaneous employment of the FRAIL scale and TFI, four distinct categories have been distinguished: (i) nonrobust physical status with multidimensional frailty, (ii) exclusive non-robust physical status, (iii) exclusive multidimensional frailty, and (iv) full robust status. Table 2 presents the differences between the four functional categories. As expected, they significantly differed in the classifying criteria, ie, the components of the FRAIL scale and TFI; however, they also revealed differences in other variables, ie, age, place of living, former occupation, education and economic level, lifestyle, satisfaction with living conditions, number of concomitant and recently experienced diseases, living in a relationship, loss of an important person or relationship, participation in senior organizations, and traffic event in the recent time.

The key specifics of these four subgroups are reflected in the prevalence of components of the FRAIL scale and TFI, which categorize elderly people as those presenting mixed functional deficits, predominant physical impairment, predominant multidimensional deficits (particularly psychological and social ones), or robust status (Table 2) statistically significant differences between these four subgroups are marked with appropriate symbols.

\section{Discussion}

In this study, two simple frailty diagnostic instruments, the FRAIL scale and TFI, were employed among communitydwelling elderly people aged 65 years or older to identify subjects at risk of functional deterioration. By combining the results of these instruments, the individuals have been 
Table I Characteristics of Participants

\begin{tabular}{|c|c|}
\hline Characteristic & $\begin{array}{l}\text { Overall Group } \\
N: 1024\end{array}$ \\
\hline $\begin{array}{l}\text { Age (years) } \\
\text { Male sex } \\
\text { Living in a city } \\
\text { Former intellectual occupation }\end{array}$ & $\begin{array}{l}72.6 \pm 6.3 \\
270(26.4) \\
746(72.9) \\
646(63.1)\end{array}$ \\
\hline $\begin{array}{l}\text { Education level } \\
\text { Primary school/High school/University }\end{array}$ & $\begin{array}{l}258(25.2) / 464(45.3) / \\
302(29.5)\end{array}$ \\
\hline $\begin{array}{l}\text { Economic status } \\
\text { Low/Moderate/High }\end{array}$ & $\begin{array}{l}152(14.8) / 835(81.5) / 37 \\
(3.6)\end{array}$ \\
\hline $\begin{array}{l}\text { Lifestyle } \\
\text { Unhealthy/Partially healthy/Healthy }\end{array}$ & $\begin{array}{l}54(5.3) / 532(52.0) / 438 \\
(42.8)\end{array}$ \\
\hline $\begin{array}{l}\text { Satisfaction with living conditions } \\
\text { Serious illness in the recent time } \\
\text { Number of chronic diseases } \\
\text { Living in a relationship } \\
\text { Death of a loved person in the recent time } \\
\text { Serious illness of a loved person in the } \\
\text { recent time } \\
\text { End of an important relationship in the } \\
\text { recent time } \\
\text { Participation in a senior organization } \\
\text { Traffic accident in the recent time } \\
\text { Criminal event in the recent time }\end{array}$ & $\begin{array}{l}903(88.2) \\
229(22.4) \\
1.9 \pm 1.6 \\
529(51.7) \\
389(38.0) \\
245(23.9) \\
70(6.8) \\
460(44.9) \\
59(5.8) \\
23(2.2)\end{array}$ \\
\hline $\begin{array}{l}\text { The FRAIL scale } \\
\text { I. Physical tiredness/fatigue } \\
\text { 2. Inability to walk up one flight of stairs } \\
\text { 3. Inability to walk } 200 \mathrm{~m} \\
\text { 4. Unexplained body mass loss } \\
\text { 5. Presence of } 5 \text { or more chronic } \\
\text { diseases } \\
\text { Total FRAIL scale score } \\
\text { Physical frailty } \\
\text { Physical pre-frailty } \\
\text { Non-robust status }\end{array}$ & $\begin{array}{l}465(45.4) \\
87(8.5) \\
101(9.9) \\
133(13.0) \\
22(2.1)\end{array}$ \\
\hline $\begin{array}{l}\text { The Tilburg Frailty Indicator (TFI) } \\
\text { I. Poor physical health } \\
\text { 2. Unexplained body mass loss } \\
\text { 3. Difficulty in walking } \\
\text { 4. Difficulty in maintaining balance } \\
\text { 5. Poor hearing } \\
\text { 6. Poor vision } \\
\text { 7. Lack of strength in hands } \\
\text { 8. Physical tiredness/fatigue } \\
\text { 9. Problems with memory } \\
\text { 10. Feeling down }\end{array}$ & $\begin{array}{l}33 \mid(32.3) \\
\text { I33 }(13.0) \\
37 \mid(36.2) \\
26 \mid(25.5) \\
358(35.0) \\
4 \mid 4(40.4) \\
283(27.6) \\
465(45.4) \\
\mid 38(13.5) \\
67 \mid(65.5)\end{array}$ \\
\hline
\end{tabular}

(Continued)
Table I (Continued).

\begin{tabular}{|l|l|}
\hline Characteristic & $\begin{array}{l}\text { Overall Group } \\
\text { N: I 024 }\end{array}$ \\
\hline II. Feeling nervous or anxious & $675(65.9)$ \\
I2. Inability to cope with problems & $188(18.4)$ \\
13. Living alone & $384(37.5)$ \\
I4. Missing other people & $682(66.6)$ \\
I5. Lack of support from other people & $185(18.1)$ \\
Total TFI score & $5.4 \pm 3.1$ \\
Multidimensional frailty & $559(54.6)$ \\
\hline
\end{tabular}

Note: Values are mean \pm SD or $n(\%)$.

categorized into four different functional subgroups according to their profiles of age-related deficits.

More than one-third (42.3\%) of the study population appeared to be physically non-robust with concomitant deficits of multidimensional frailty, particularly concerning psychological and social aspects. In terms of disability prevention, such subjects would require a comprehensive intervention covering not only their physical decline but also their mood disturbances and their social deficits. Physical tiredness, a sense of poor physical health, difficulties in walking and maintaining balance, hearing and vision problems, and a lack of strength in hands were the most prevalent physical limitations identified by the FRAIL scale and TFI in this subgroup. Numerous studies show that regular physical exercises diminish frailty consequences, ie, falls, cardiopulmonary and musculoskeletal dysfunctions, and poor functional capacity. ${ }^{14-17}$ Moreover, physical activity improves prognosis in a dose-response fashion, and individuals at higher risk may benefit from physical activity to a greater extent than those at a lower risk. ${ }^{18}$ Hearing and vision problems may be treated with appropriate glasses and hearing devices - this is critical because such sensory deficits predispose to frailty development. ${ }^{19-21}$ Feeling down, nervousness and anxiety, as well as missing other people were the most dominant psychological and social problems among this study subgroup. In fact, lonely aging is associated with an unavoidable awareness of elapsing time, which reminds elderly people of the approaching end of life, and significantly affects their psychological condition. ${ }^{10}$ In a study by Gobbens et al, feeling down was the strongest frailty component influencing all facets of quality of life. ${ }^{22}$ Indeed, depression is a common element in the aging process, and hence, it should be diagnosed early 
Table 2 Comparison of Four Different Functional Categories of the Participants

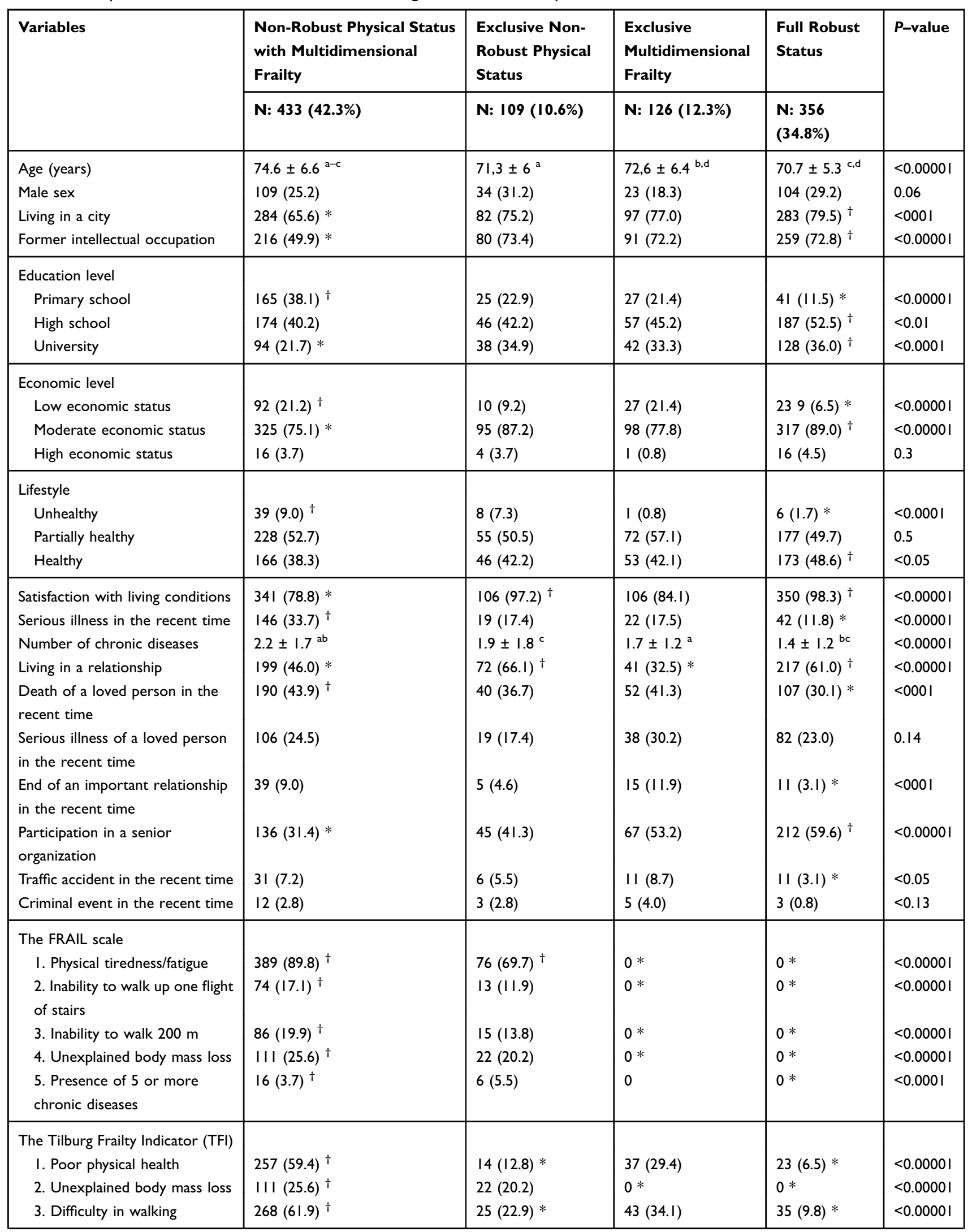

(Continued) 
Table 2 (Continued).

\begin{tabular}{|c|c|c|c|c|c|}
\hline \multirow[t]{2}{*}{ Variables } & $\begin{array}{l}\text { Non-Robust Physical Status } \\
\text { with Multidimensional } \\
\text { Frailty }\end{array}$ & $\begin{array}{l}\text { Exclusive Non- } \\
\text { Robust Physical } \\
\text { Status }\end{array}$ & $\begin{array}{l}\text { Exclusive } \\
\text { Multidimensional } \\
\text { Frailty }\end{array}$ & $\begin{array}{l}\text { Full Robust } \\
\text { Status }\end{array}$ & \multirow[t]{2}{*}{$P$-value } \\
\hline & N: 433 (42.3\%) & N: 109 (10.6\%) & N: 126 (12.3\%) & $\begin{array}{l}N: 356 \\
(34.8 \%)\end{array}$ & \\
\hline $\begin{array}{l}\text { 4. Difficulty in maintaining } \\
\text { balance }\end{array}$ & $201(46.4)^{\dagger}$ & $12(11.0) *$ & $31(24.6)$ & $17(4.8) *$ & $<0.00001$ \\
\hline 5. Poor hearing & $209(48.3)^{\dagger}$ & $23(21.1) *$ & $61(48.4)^{\dagger}$ & $65(18.3) *$ & $<0.00001$ \\
\hline 6. Poor vision & $257(59.4)^{\dagger}$ & $28(25.7) *$ & $68(54.0)^{\dagger}$ & $61(17.1) *$ & $<0.0000$ I \\
\hline 7. Lack of strength in hands & $225(52.0)^{\dagger}$ & $11(10.1) *$ & $29(23.0)$ & $18(5.1) *$ & $<0.00001$ \\
\hline 8. Physical tiredness/fatigue & $389(89.8)^{\dagger}$ & $76(69.7)^{\dagger}$ & $0 *$ & $0 *$ & $<0.00001$ \\
\hline 9. Problems with memory & $104(24.0)^{\dagger}$ & $5(4.6) *$ & $20(15.9)$ & $9(2.5) *$ & $<0.00001$ \\
\hline 10. Feeling down & $365(84.3)^{\dagger}$ & $44(40.4) *$ & $116(92.1)^{\dagger}$ & $146(4 \mid .0) *$ & $<0.00001$ \\
\hline II. Feeling nervous or anxious & $35 I(8 I .1)^{\dagger}$ & $43(39.4) *$ & $109(86.5)^{\dagger}$ & $172(48.3) *$ & $<0.00001$ \\
\hline $\begin{array}{l}\text { 12. Inability to cope with } \\
\text { problems }\end{array}$ & $125(28.9)^{\dagger}$ & $3(2.8) *$ & $42(33.3)^{\dagger}$ & $18(5.1) *$ & $<0.00001$ \\
\hline 13. Living alone & $179(4 \mid .3)$ & $22(20.2) *$ & $80(63.5)^{\dagger}$ & $103(28.9) *$ & $<0.00001$ \\
\hline 14. Missing other people & $342(79.0)^{\dagger}$ & $42(38.5) *$ & $114(90.5)^{\dagger}$ & $184(51.7) *$ & $<0.00001$ \\
\hline $\begin{array}{l}\text { 15. Lack of support from other } \\
\text { people }\end{array}$ & $110(25.4)^{\dagger}$ & $6(5.5) *$ & $41(32.5)^{\dagger}$ & $28(7.9) *$ & $<0.00001$ \\
\hline
\end{tabular}

Notes: Values are mean \pm SD or $n(\%)$. P-value refers to the Kruskal-Wallis test or chi-square test where appropriate; same letters (ie, superscript a, b, c, $d$ ) next to the age and number of chronic diseases correspond to the variables which significantly differ between each other with $P$-values less than 0.013 for all in Tukey-Kramer's posthoc analysis; ${ }^{\dagger}$ Denotes that the observed variable frequency is significantly higher than expected frequency, but $*$ denotes that the observed frequency is significantly lower, with Bonferroni corrected $P$-values less than 0.006 for all.

and adequately treated in order to improve people's mood and their motivation for an active life. ${ }^{23-25}$ Poor social life is one of the principal reasons for low quality of life in elderly people, and loneliness seems to be an independent predictor for their functional deterioration and mortality. ${ }^{22,26-30}$ Furthermore, for the frail elderly individuals, social relationship is the most important factor for their existence, while non-frail older subjects consider health as the most critical one. ${ }^{27}$ Therefore, appropriate social programs involving families and local communities should be established in order to mitigate loneliness associated with aging in this subgroup.

A functionally opposite category to the previous one was the fully robust subgroup which constituted almost $35 \%$ of the study population. Despite the fact that none of them presented any component of the FRAIL scale and they did not fulfill criteria for multidimensional frailty (according to TFI), some of them (ie, about 40-50\%) exhibited psychological and social deficits, ie, feeling down, nervousness and anxiety, and missing other people. Thus, even in this robust subgroup, people would benefit from health improvements concerning their psychological and social life.
Two other subgroups have been distinguished as a consequence of the discordant outcomes of the FRAIL scale and TFI, ie, an exclusively physically non-robust subgroup (10.6\%), and an exclusively multidimensionally frail subgroup (12.3\%). The first cohort represents subjects whose principal issues were tiredness and fatigue (ie, $69.7 \%$ ), but the prevalence of deficits in other dimensions did not exceed $41 \%$. Therefore, the main intervention in this subgroup should be directed to improving their muscular strength and endurance. However, the second subgroup almost entirely (ie, about 90\%) presented psychological and social deficits with no signs of physical impairments in the FRAIL scale. Hence, such a specific subgroup should undergo a psychological or psychiatric diagnostic evaluation with an appropriate professional support. Of note, the identification of some psychological or mental deficits does not mean a diagnosis of real disorder; however, this should prompt subjects to seek specialist advice; likewise, recognition of social deficits should initiate interventions to prevent social degradation.

A huge number of different frailty diagnostic instruments have been proposed so far; however, in our study, we have chosen the FRAIL scale and TFI due to their 
simplicity and validity as confirmed in many studies. ${ }^{2-9}$ The FRAIL scale was designed to capture frail subjects (ie, if at least 3 criteria are met); however, in this study, the instrument was used to identify physically non-robust individuals, ie, subjects with frailty or pre-frailty (ie, if at least 1 criterion was met). This way, the FRAIL scale became very sensitive in recognizing individuals at risk, and its sensitivity corresponded to the sensitivity of TFI as a result, they captured a similar proportion of the study population, $52.9 \%$ and $54.6 \%$, respectively. However, the selected subgroups were not the same, and hence, it was possible to distinguish subjects presenting different profiles of deficits. The comparison of the subgroups reflects their characteristics, and thus, one is able to learn about their functional details, eg, the third subgroup (exclusive multidimensional frailty) mainly presents psychological and social deficits, whereas the first subgroup (ie, nonrobust physical status with multidimensional frailty) presents all kinds of deficits. The combination of the FRAIL scale and TFI may be used by both seniors themselves or professionals who deal with older patients to detect their deficits and plan an individualized management strategy, eg, correction of vision or hearing problems, mental training, social activities, etc.

Usually, unidimensional and multidimensional tools are compared in terms of their ability to detect frail subjects and their accuracy to predict adverse outcomes, but little is known about whether a combination of such tools improves characterization of the age-related abnormalities. ${ }^{8}$ Oo Het Veld et al tested if combinations of two of the following frailty instruments: PFP, Frailty Index, TFI, and Groningen Frailty Indicator, improve the predictive power for dependency, mortality, and hospitalization in community-dwelling older people. ${ }^{31}$ The authors revealed that the application of two frailty instruments, sequential or parallel, did not improve the predictive validity - however, this was an observational study with no intervention among the participants. Therefore, whether a more specific recognition of various deficit profiles helps to individualize an approach to the elderly problems and eventually yields better outcomes, needs to be validated in prospective studies. For now, the high sensitivity of the FRAIL scale and TFI in detecting functional abnormalities implies their usage for screening purposes and for health promotion and preventative interventions.

Despite all the above findings, this study, however, has some limitations which need to be noted. Self-assessment of the frailty state without objective information on the functional condition does not preclude some bias. The subjects were predominantly women, which is probably due to the fact that questionnaires were disseminated during healthy lifestyle promoting meetings certainly attracting more women than men; this may limit the generalizability of the findings. The FRAIL scale was used as a diagnostic tool for non-robust status in this study, but it was developed to diagnose frail and pre-frail state. Finally, the cross-sectional design of the research and a lack of outcome measures do not allow the establishment of the predictive value of the four functional categories distinguished in this study. Therefore, future studies are necessary to verify the causal relationships between these categories and health outcomes.

\section{Conclusion}

The FRAIL scale and the Tilburg Frailty Indicator are simple and useful tools for frailty screening and for the identification of various profiles of functional deficits in communitydwelling elderly people. By a combination of these tools, four different functional categories can be distinguished which may require individualized interventions for improving the functional status. Due to the simplicity, the FRAIL scale and TFI may be used by both seniors themselves and professionals dealing with older patients to plan a proper management strategy or seek specialist advice. Further studies are needed to investigate if this approach is useful for preventative and therapeutic interventions among elderly people.

\section{Disclosure}

The authors report no conflicts of interest in this work.

\section{References}

1. Buchner D, Wagner E. Preventing frail health. Clin Geriatr Med. 1992;8(1):1-17. doi:10.1016/S0749-0690(18)30494-4

2. Fried LP, Tangen CM, Walston J, et al. Frailty in older adults: evidence for a phenotype. J Gerontol a Biol Sci Med Sci. 2001;56(3):M146M156. doi:10.1093/gerona/56.3.M146

3. Markle-Reid M, Browne G. Conceptualizations of frailty in relations to older adults. J Adv Nurs. 2003;44(1):58-68. doi:10.1046/j.13652648.2003.02767.x

4. Abellan van Kan G, Rolland YM, Morley JE, Vellas B. Frailty: toward a clinical definition. $J$ Am Med Dir Assoc. 2008;9(2):71-72. doi:10.1016/j.jamda.2007.11.005

5. Gobbens RJ, van Assen MA, Luijkx KG, Wijnen-Sponselee MT, Schols JM. The Tilburg frailty indicator: psychometric properties. J Am Med Dir Assoc. 2010;11(5):344-355. doi:10.1016/j.jamda. 2009.11.003

6. Abellan van Kan G, Rolland Y, Bergman H, Morley JE, Kritchevsky SB, Vellas B. The I.A.N.A task force on frailty assessment of older people in clinical practice. J Nutr Health Aging. 2008;12 (1):29-37. doi:10.1007/BF02982161 
7. Theou O, Brothers TD, Mitnitski A, Rockwood K. Operationalization of frailty using eight commonly used scales and comparison of their ability to predict all-cause mortality. J Am Geriatr Soc. 2013;61 (9):1537-1551. doi:10.1111/jgs. 12420

8. Roppolo M, Mulasso A, Gobbens RJ, Mosso CO, Rabaglietti E. A comparison between uni- and multidimensional frailty measures: prevalence, functional status, and relationships with disability. Clin Interv Aging. 2015;10:1669-1678. doi:10.2147/CIA.S92328

9. Diaz de Leon Gonzalez E, Gutierrez Hermosillo H, Martinez Beltran JA, et al. Validation of the FRAIL scale in mexican elderly: results from the mexican health and aging study. Aging Clin Exp Res. 2016;28(5):901-908. doi:10.1007/s40520-015-0497-y

10. Sacha J, Sacha M, Sobon J, Borysiuk Z, Feusette P. Is it time to begin a public campaign concerning frailty and pre-frailty? A review article. Front Physiol. 2017;8:484. doi:10.3389/fphys.2017.00484

11. Uchmanowicz I, Jankowska-Polańska B, Uchmanowicz B, Kowalczuk K, Gobbens RJ. Validity and reliability of the polish version of the tilburg frailty indicator (TFI). $J$ Frailty Aging. 2016;5(1):27-32. doi:10.14283/jfa.2015.66

12. Uchmanowicz I, Nessler J, Gobbens R, et al. Coexisting frailty with heart failure. Front Physiol. 2019;10:791. doi:10.3389/fphys.2019. 00791

13. Beasley TM, Schumacker RE. Multiple regression approach to analyzing contingency tables: post hoc and planned comparison procedures. J Exp Educ. 1995;64(1):79-93. doi:10.1080/00220973. 1995.9943797

14. Vagetti GC, Barbosa Filho VC, Moreira NB, Oliveira V, Mazzardo O, Campos W. Association between physical activity and quality of life in the elderly: a systematic review, 2000-2012. Braz J Psychiatry. 2014;36(1):76-88. doi:10.1590/1516-4446-2012-0895

15. de Labra C, Guimaraes-Pinheiro C, Maseda A, Lorenzo T, Millán-Calenti JC. Effects of physical exercise interventions in frail older adults: a systematic review of randomized controlled trials. BMC Geriatr. 2015;15:154. doi:10.1186/s12877-015-0155-4

16. Bauman A, Merom D, Bull FC, Buchner DM, Fiatarone Singh MA. Updating the evidence for physical activity: summative reviews of the epidemiological evidence, prevalence, and interventions to promote active aging. Gerontologist. 2016;56(Suppl 2):S268-280. doi:10.1093/geront/gnw031

17. Dent E, Lien C, Lim WS, et al. The Asia-Pacific clinical practice guidelines for the management of frailty. J Am Med Dir Assoc. 2017;18(7):564-575. doi:10.1016/j.jamda.2017.04.018

18. Jeong SW, Kim SH, Kang SH, et al. Mortality reduction with physical activity in patients with and without cardiovascular disease. Eur Heart J. 2019;40(43):3547-3555. doi:10.1093/eurheartj/ehz564

19. Kamil RJ, Betz J, Powers BB, et al. Association of hearing impairment with incident frailty and falls in older adults. $J$ Aging Health. 2016;28(4):644-660. doi:10.1177/0898264315608730
20. Liljas AEM, Carvalho LA, Papachristou E, et al. Self-reported hearing impairment and incident frailty in english community-dwelling older adults: a 4-year follow-up study. J Am Geriatr Soc. 2017;65 (5):958-965. doi:10.1111/jgs.14687

21. Liljas AEM, Carvalho LA, Papachristou E, et al. Self-reported vision impairment and incident prefrailty and frailty in english community-dwelling older adults: findings from a 4-year follow-up study. J Epidemiol Community Health. 2017;71(11):1053-1058. doi:10.1136/jech-2017-209207

22. Gobbens RJ, van Assen MA. Associations between multidimensional frailty and quality of life among Dutch older people. Arch Arch Gerontol Geriatr. 2017;73:69-76. doi:10.1016/j.archger.2017.07.007

23. Alexopoulos GS. Depression in the elderly. Lancet. 2005;365 (9475):1961-1970. doi:10.1016/S0140-6736(05)66665-2

24. Chu W, Chang SF, Ho HY, Lin HC. The relationship between depression and frailty in community-dwelling older people: a systematic review and meta-analysis of 84,351 older adults. J Nurs Scholarsh. 2019;51(5):547-559. doi:10.1111/jnu.12501

25. Krause M, Gutsmiedl K, Bighelli I, Schneider-Thoma J, Chaimani A, Leucht S. Efficacy and tolerability of pharmacological and non-pharmacological interventions in older patients with major depressive disorder: A systematic review, pairwise and network meta-analysis. Eur Neuropsychopharmacol. 2019;29(9):1003-1022. doi:10.1016/j.euroneuro.2019.07.130

26. Gabriel Z, Bowling A. Quality of life from the perspectives of older people. Ageing Soc. 2004;24(5):675-691. doi:10.1017/S0144686X 03001582

27. Puts MT, Shekary N, Widdershoven G, Heldens J, Lips P, Deeg DJ. What does quality of life mean to older frail and non-frail community-dwelling adults in the Netherlands? Qual Life Res. 2007;16(2):263-277. doi:10.1007/s11136-006-9121-0

28. Mehra S, Dadema T, Kröse BJ, et al. Attitudes of older adults in a group-based exercise program toward a blended intervention; a focus-group study. Front Psychol. 2016;7:1827. doi:10.3389/fpsyg. 2016.01827

29. Luo Y, Hawkley LC, Waite LJ, Cacioppo JT. Loneliness, health, and mortality in old age: a national longitudinal study. Soc Sci Med. 2012;74(6):907-914. doi:10.1016/j.socscimed.2011.11.028

30. Perissinotto CM, Stijacic Cenzer I, Covinsky KE. Loneliness in older persons: a predictor of functional decline and death. Arch Intern Med. 2012;172(14):1078-1083. doi:10.1001/archinternmed.2012.1993

31. Op Het Veld LPM, van Rossum E, Kempen GIJM, Beurskens AJHM, Hajema KJ, de Vet HCW. Can the combined use of two screening instruments improve the predictive power of dependency in (instrumental) activities of daily living, mortality and hospitalization in old age? J Frailty Aging. 2019;8(4):180-185. doi:10.14283/jfa.2019.17
Clinical Interventions in Aging

\section{Publish your work in this journal}

Clinical Interventions in Aging is an international, peer-reviewed journal focusing on evidence-based reports on the value or lack thereof of treatments intended to prevent or delay the onset of maladaptive correlates of aging in human beings. This journal is indexed on PubMed Central, MedLine, CAS, Scopus and the Elsevier
Bibliographic databases. The manuscript management system is completely online and includes a very quick and fair peer-review system, which is all easy to use. Visit http://www.dovepress.com/ testimonials.php to read real quotes from published authors. 